\title{
Real-World Analysis of Dispensed IUs of Coagulation Factor IX and Resultant Expenditures in Hemophilia B Patients Receiving Standard Half-Life Versus Extended Half-Life Products and Those Switching from Standard Half-Life to Extended Half-Life Products
}

\author{
Bartholomew J. Tortella, MD, MBA; José Alvir, DrPH; Margaret McDonald, PhD; Dean Spurden, PhD; \\ Patrick F. Fogarty, MD; Amit Chhabra, MBBS, MPH; and Andreas M. Pleil, PhD
}

\begin{abstract}
BACKGROUND: Hemophilia B requires replacement therapy with factor IX (FIX) coagulation products to treat and prevent bleeding episodes. A recently introduced extended half-life (EHL) recombinant FIX replacement product provided the opportunity to compare the amount of dispensed factor and expenditures for EHL treatment compared with a standard half-life (SHL) product.
\end{abstract}

OBJECTIVE: To determine factor international units (IUs) dispensed and expenditures associated with switching from nonacog alfa, the most commonly used SHL replacement product, to eftrenonacog alfa, an EHL FIX replacement product.

METHODS: Two U.S. claims databases were analyzed. A large national specialty pharmacy dispensation claims database was used to identify the number of IUs dispensed and monthly charges for all patients with hemophilia B from April 2015 to June 2016. Truven Health MarketScan Research Databases (January 2010-July 2016) were used to identify IUs and expenditures for patients with claims data for at least 3 months before and after switching from the SHL to the EHL product. Medians for IUs and expenditures are presented to accommodate for skewness of data distribution.

RESULTS: The national specialty pharmacy database analysis included 296 patients with moderate or severe hemophilia B (233 on SHL; 94 on EHL). Median monthly factor dispensed was $11 \%$ lower $(2,142 \mathrm{IU})$ in the EHL versus SHL cohort over the study period, while individual monthly reductions ranged from $32 \%$ to $47 \%$ (9,838 IU to $16,514 \mathrm{IU})$. Using the wholesale acquisition cost, the median per-patient monthly factor expenditures over the 15 -month study period were $94 \%$ higher $(\$ 23,005)$ for the EHL than for the SHL product. Individual median monthly expenditure differences ranged from $15 \%(\$ 6,562)$ to $49 \%(\$ 19,624)$. In the Truven database, 14 patients switched from the SHL to the EHL product. The amount of factor dispensed was variable; in the 1-year period before and after the switch from the SHL to the EHL product, mean IUs dispensed decreased by $3,005 \mathrm{IU}$, while median IUs dispensed increased by $4,775 \mathrm{IU}$. Factor replacement expenditures were higher after switching from the SHL to the EHL product in each of the 3-month periods examined before versus after the switch.

CONCLUSIONS: This analysis of real-world data showed that switching from the SHL to the EHL product was associated with higher expenditures. Increased expenditures noted in the first 3 months after switching may be related to initial stocking up of the EHL product, but expenditures were sustained throughout the 1-year period of data analysis. Further analysis of these findings with larger numbers of patients should be explored.

J Manag Care Spec Pharm. 2018;24(7):643-53

Copyright $\odot 2018$, Academy of Managed Care Pharmacy. All rights reserved.

\section{What is already known about this subject}

The standard of care for the treatment and prevention of bleeding events in patients with hemophilia B is replacement of factor IX (FIX) with plasma-derived or recombinant FIX (rFIX) clotting factor concentrates.

Total weekly dosing with a conjugated extended half-life (EHL) rFIX product is approximately half that of a standard half-life (SHL) rFIX product.

EHL products were priced to create parity with SHL products on an annual expenditure on factor replacement therapy basis as demonstrated in their respective clinical studies.

\section{What this study adds}

In these analyses of real-world data, expenditures on EHL rFIX products were higher compared with those for SHL products, based on wholesale acquisition cost values and claims cost data. Higher expenditures were driven in part by greater-thanexpected actual EHL product dispensed compared with published EHL product dosing.

Additional real-world experience is needed to better understand EHL product dosing regimens and patient behavior.

$\mathrm{H}$ emophilia B is caused by a mutation of the gene for factor IX (FIX), leading to a deficiency in the activity of coagulation FIX, which is part of the intrinsic coagulation pathway. ${ }^{1,2}$ Hemophilia B represents $15 \%-20 \%$ of all hemophilia cases and occurs in approximately 1 in 30,000 live male births across all racial and ethnic groups., ${ }^{1,2}$ Deficiency of FIX leads to reduced activity of the tenase complex and affects the ability to generate thrombin, which is essential to the formation and maintenance of a stable clot. The level of FIX coagulant activity determines the degree of bleeding tendency (normal FIX activity, 100\% $\pm 50 \%$ ), which is classified as mild (5\%-40\%), moderate (1\%-5\%), or severe $(<1 \%){ }^{3}$ Severe FIX deficiency is characterized by spontaneous or trauma-induced 
bleeding into soft tissue, muscle, or joints, and without optimal treatment, chronic pain, disability, and a reduced quality of life. ${ }^{1,2}$ The standard of care for the treatment and prevention of bleeding events and their complications centers on replacement of FIX with plasma-derived or recombinant FIX clotting factor concentrates. ${ }^{1}$ In the United States, clotting factor availability is not constrained and patients use factor at home, as needed, and reorder to maintain an appropriate in-home inventory.

Recombinant-based clotting factor concentrate replacement products have evolved since the 1980s, when the plasmaderived products were shown to be associated with the transmission of hepatitis B and C viruses and human immunodeficiency virus. ${ }^{4}$ Cloning of the FIX gene allowed for use of recombinant technology to reduce the risk of infectious transmission from plasma-derived replacement products. ${ }^{2,5}$ The first recombinant FIX (rFIX) product was nonacog alfa (BeneFIX, Pfizer), ${ }^{6}$ which is structurally and functionally similar to endogenous FIX. ${ }^{2}$ With longer pharmacokinetic sampling (up to 96 hours), the half-life of nonacog alfa was determined to

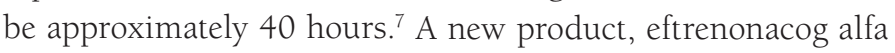
(Alprolix, Biogen), ${ }^{8}$ was developed by covalently fusing a single molecule of rFIX to the dimeric Fc domain of immunoglobulin $G$ to prolong the half-life. ${ }^{9}$ This product has a half-life 3 to 6 times longer than that of native or standard half-life (SHL) rFIX products. ${ }^{10}$ When introduced, the conjugated extended half-life (EHL) rFIX treatment was priced at parity with SHL products by balancing the lower expected international unit (IU) dispensed factor with the higher per-unit price and similar efficacy, based on annualized bleeding rates, as demonstrated in clinical studies. ${ }^{9,11,12}$

The objectives of this analysis were to provide profiles of factor IUs dispensed and expenditures for an SHL product (nonacog alfa) versus an EHL product (eftrenonacog alfa) on a population level of specialty pharmacy claims and on a patient level for patients whose switch from the SHL to EHL product could be tracked in an administrative claims database at the individual patient level.

\section{Methods}

\section{Study Design}

This retrospective cohort study compared male patients with hemophilia B who were using either of the SHL or EHL rFIX replacement products. De-identified claims data were obtained from 2 sources to assess IUs dispensed and expenditures for overall rFIX replacement products (population-level analysis) and for those specifically switched from an SHL to an EHL product (patient-level analysis). Data were collected for individuals on nonacog alfa (the most commonly used SHL replace- ment product) and eftrenonacog alfa (the only EHL product with data available during this period).

\section{Population-Level Analysis}

A large national specialty pharmacy dispensation claims database was used to identify monthly IUs dispensed and charges for all patients with moderate (FIX level 1\%-5\%) or severe (FIX level $<1 \%$ ) hemophilia B (diagnosis code of International Classification of Diseases, Ninth Revision, Clinical Modification [ICD-9-CM] 286.1 or Tenth Revision [ICD-10-CM] D67) from April 2015 to June 2016. The variables available in the national specialty pharmacy database were limited to details on the factor replacement product prescription, including date of shipment, factor and units dispensed, age (or year of birth), payer name, and physician location. However, factor replacement product regimen and severity of hemophilia B, items not available in traditional claims data, were self-reported patient data fields in the database and were used. The analysis reports differences between groups and does not provide data on patients who switched from 1 therapy to another.

\section{Patient-Level Analysis}

The Truven Health MarketScan Research Databases were used to identify claims from January 2010 to July 2016 (data range selected to permit the largest number of patients to be analyzed over time) for patients who had a diagnosis code for hemophilia B (using the same ICD criteria as above), a prescription for an EHL factor replacement product, a prior prescription for an SHL factor replacement product, and claims data for at least 3 months before and 3 months after switching from an SHL to an EHL product. For the patient-level analysis, the patient needed to have 1 quarter worth of enrollment/claims data before and after the switch from an SHL to an EHL product; individuals who did not have 90 days of follow-up for the quarter were not included. Switching was determined by the fact that subsequent claims in the database were no longer from the SHL product but from the EHL product.

This database provides detailed data of IUs dispensed and expenditures for both inpatient and outpatient health care services for approximately 100 million privately insured members (employees, dependents, and retirees) in the United States with primary or Medicare supplemental coverage through a variety of health plans, including fee-for-service, point-of-service, and capitation. Eftrenonacog alfa was first used in June 2014. Successive 3-month intervals (1-3, 4-6, 7-9, and 10-12 months) immediately before and after the switch were evaluated.

\section{Assessments}

The key outcome measures were IUs of factor dispensed and direct expenditures for the rFIX replacement products. Overall 
Real-World Analysis of Dispensed IUs of Coagulation Factor IX and Resultant Expenditures in Hemophilia B Patients Receiving Standard Half-Life Versus Extended Half-Life Products and Those Switching from Standard Half-Life to Extended Half-Life Products

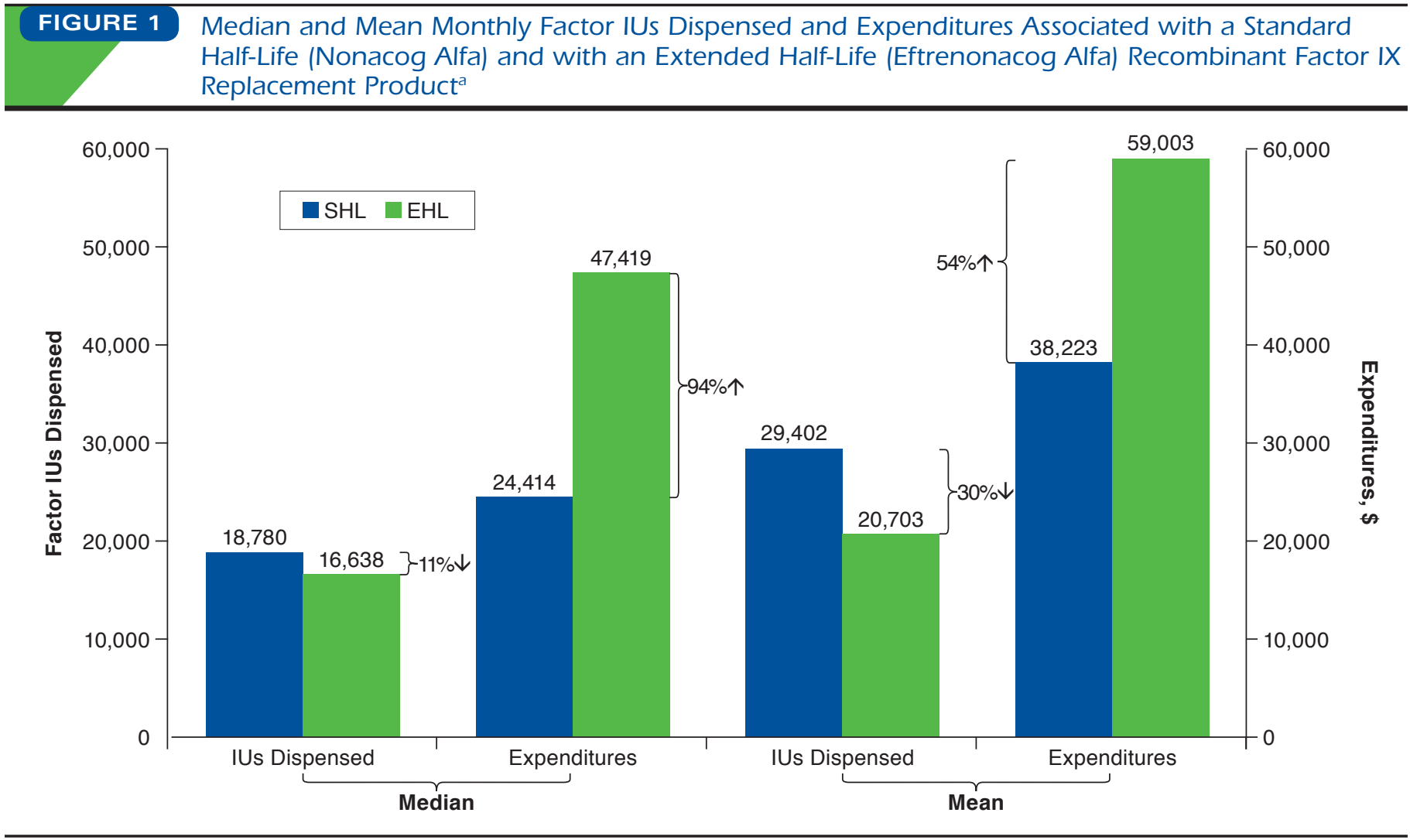

Note: Expenditures are based on 2015 dollars.

a National Specialty Pharmacy Database.

EHL=extended half-life; IUs=international units; SHL=standard half-life.

expenditures from the national specialty pharmacy database were calculated per patient per month (PPPM), consistent with the monthly updates provided. Wholesale acquisition cost (WAC) prices for 2015, provided by AnalySource (http://classic. analysource.com/?switchsite=Y), were used to calculate expenditures (nonacog alfa $=\$ 1.30 / \mathrm{IU}$; eftrenonacog alfa $=\$ 2.85 / \mathrm{IU}$ ). The WAC was used because it is the most commonly used benchmark in pharmacy purchasing of drugs, and many pharmacies procure their drugs through the wholesaler channel. Average expenditures PPPM while on the SHL or the EHL product (as determined by product class for which the insurance claim was submitted) were calculated by summing all available monthly data and dividing by the number of months from the first to the last month in which factor shipment occurred.

For the patient-level analysis using Truven data, expenditures were measured over 3-month (quarterly) periods, centered on the time of the patient's switch, as defined by the first month that an EHL claim was paid. Incomplete quarters (indi- viduals who did not have 90 days of follow-up for the quarter) were not included. Expenditures (usually a medical benefit) were calculated using the Truven variable that measures gross payments to a provider for a service in which payment equals the amount eligible for payment under the medical plan terms after applying rules, such as discounts, but before applying coordination of benefits, copayments, and deductibles. Average quarterly expenditures and IUs dispensed before and after the switch were calculated using the quarters with data available.

All data were summarized descriptively. Median values (and their corresponding interquartile ranges [IQRs]) are provided to characterize the distribution of IUs dispensed and expenditures. These values are more robust owing to the presence of outliers, which are common in data for dispensed IUs and expenditures. Analyses were completed using SAS software package 9.4 (SAS Institute, Cary, NC) on Red Hat Enterprise Linux (Red Hat, Raleigh, NC). 
Real-World Analysis of Dispensed IUs of Coagulation Factor IX and Resultant Expenditures in Hemophilia B Patients Receiving Standard Half-Life Versus Extended Half-Life Products and Those Switching from Standard Half-Life to Extended Half-Life Products

\section{TABLE 1 Population-Level Analysis of Average Monthly IUs of Factor Dispensed and Expenditures of} Recombinant Factor IX Replacement Products ${ }^{a}$

\begin{tabular}{|c|c|c|c|c|c|c|}
\hline \multirow[b]{2}{*}{ Parameter } & \multicolumn{2}{|c|}{ Prophylaxis Patients } & \multicolumn{2}{|c|}{$\begin{array}{l}\text { Episodic Treatment } \\
\text { On-Demand Patients }\end{array}$} & \multicolumn{2}{|c|}{ All Patients } \\
\hline & IUs Dispensed & Expenditures, \$ & IUs Dispensed & Expenditures, \$ & IUs Dispensed & Expenditures, \$ \\
\hline EHL cohort, $n$ & \multicolumn{2}{|c|}{83} & \multicolumn{2}{|c|}{10} & \multicolumn{2}{|c|}{$94 b$} \\
\hline Median & 16,939 & 48,276 & 14,364 & 40,936 & 16,638 & 47,419 \\
\hline IQR & $10,283-26,428$ & $29,308-75,319$ & $12,968-27,817$ & $36,959-79,279$ & $10,486-27,017$ & $29,886-76,999$ \\
\hline Mean (SD) & $20,516(14,495)$ & $58,469(41,309)$ & $22,630(16,770)$ & $64,495(47,795)$ & $20,703(14,596)$ & $59,003(41,598)$ \\
\hline SHL cohort, $n$ & \multicolumn{2}{|c|}{118} & \multicolumn{2}{|c|}{115} & \multicolumn{2}{|c|}{233} \\
\hline Median & 27,469 & 35,710 & 12,450 & 16,185 & 18,780 & 24,414 \\
\hline IQR & $16,151-44,061$ & $20,996-57,280$ & $5,271-28,290$ & $6,853-36,777$ & $9,725-34,387$ & $12,643-44,703$ \\
\hline Mean (SD) & $37,409(40,908)$ & $48,631(53,180)$ & $20,974(25,778)$ & $27,267(33,511)$ & $29,402(35,262)$ & $38,223(45,841)$ \\
\hline $\begin{array}{l}\text { Difference in median IUs/dispensed } \\
\text { expenditures, \$ (EHL-SHL product) }\end{array}$ & $\downarrow 10,530$ & $\uparrow 12,566$ & $\uparrow 1,914$ & $\uparrow 24,751$ & $\downarrow 2,142$ & $\uparrow 23,005$ \\
\hline $\begin{array}{l}\text { Median IUs dispensed/expenditures } \\
\text { difference, \% (EHL-SHL product) }\end{array}$ & $\downarrow 38$ & $\uparrow 35$ & $\uparrow 15$ & $\uparrow 153$ & $\downarrow 11$ & 个 94 \\
\hline \multicolumn{7}{|c|}{$\begin{array}{l}\text { Note: Data presented for the SHL product are specifically for nonacog alfa, and data presented for the EHL product are specifically for eftrenonacog alfa. } \\
\text { a National Specialty Pharmacy Database, } N=296 \text {. }\end{array}$} \\
\hline
\end{tabular}

\section{Results}

\section{Analysis of the National Specialty Pharmacy Database (Population-Level View)}

Monthly IUs dispensed and expenditures were analyzed for 296 patients identified as having moderate or severe hemophilia B. In total, 233 patients received the SHL product and 94 received the EHL product during the 15-month study period. Some of these patients received both the SHL and EHL products over the study period. The majority of patients received rFIX replacement as a prophylactic regimen (57.8\%), and $41.2 \%$ received rFIX replacement as episodic on-demand treatment. Overall, $80 \%$ of the patients were $<40$ years of age, and $63 \%$ of patients had their disease reported as severe. Median values are presented to avoid skewing, which can occur with high numeric outliers (mean and median data are presented in tables).

IUs Dispensed. The median monthly factor IUs dispensed for all patients ranged from 29,776 IU to 34,940 IU for the SHL product and from 16,340 IU to 20,912 IU for the EHL product (Appendix A, available in online article). Median monthly IUs dispensed for all patients over the study period were lower in the EHL cohort by 2,142 IU (11\% reduction; Figure 1; Table 1), ranging from $32 \%$ to $47 \%$ reduction compared with SHL users (median monthly use difference, 9,838 IU to 16,514 IU; Appendix A). This was true for patients on prophylaxis $(10,530$ IU lower) but not for those on episodic on-demand treatment (1,914 IU higher).
Expenditures. The median factor expenditures PPPM over the study period were $\$ 23,005$ higher (94\% increase) in the EHL product cohort $(\$ 47,419)$ compared with the SHL product cohort $(\$ 24,414$; Figure 1 ; Table 1$)$. This was true both for patients on prophylaxis ( $\$ 12,566$ higher) and those on episodic on-demand treatment $(\$ 24,751)$. The median monthly expenditures for all patients ranged from $\$ 38,709$ to $\$ 45,422$ for the SHL product and from $\$ 46,569$ to $\$ 59,599$ for the EHL product (Appendix A). Individual median monthly differences for all patients in expenditures ranged from \$6,562 (15\% difference between the SHL and EHL products) to a high of \$19,624 (49\% difference between the SHL and EHL products) per month.

Mean monthly expenditures for all patients on rFIX replacement products over the study period were 54\% higher $(\$ 20,780)$ in the EHL cohort $(\$ 59,003 \pm \$ 41,598)$ than in the SHL cohort $(\$ 38,223 \pm \$ 45,841$; Figure 1 ; Table 1$)$. The highest mean monthly EHL product expenditure for all patients was $\$ 82,506$, while the lowest was $\$ 55,750$. The highest mean monthly expenditure for the SHL product was $\$ 61,128$, while the lowest was $\$ 48,026$ (Appendix A).

The differences in factor IUs (smaller) and expenditures (larger) when these were examined over the entire period compared with the individual monthly expenditures and factor IU differences indicate variations in administrative payment dates, which may be out of strict month synchronization for factor IU delivery and actual payment. 

(Nonacog Alfa) to an Extended Half-Life (Eftrenonacog Alfa) Recombinant Factor IX Replacement Product, by 3-Month Intervals Before and After Switcha

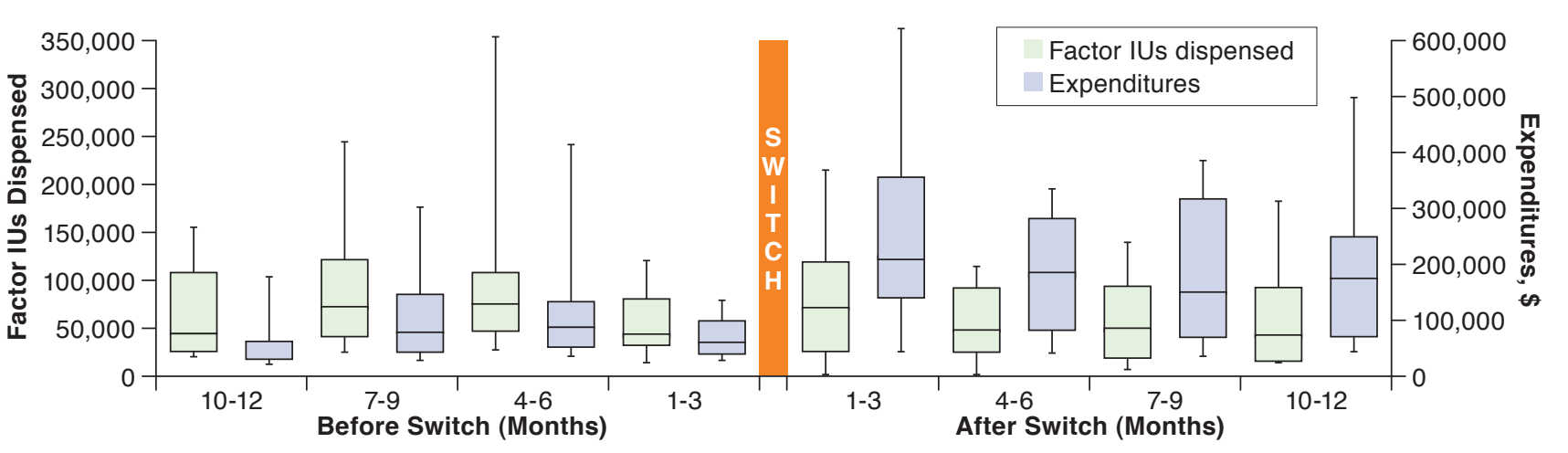

Notes: Expenditures are based on 2015 dollars. Box $=25$ th and 75 th percentiles; crossbar = median; whiskers = minimum and maximum values.

aTruven database.

IUs=international units.

\section{Analysis of the Truven Database (Switch from the SHL to EHL rFIX Replacement Product; Patient-Level View)}

Overall, 14 patients who switched from the SHL product to the EHL product were identified from the Truven database. Mean (standard deviation) age in the immediate before and after switch periods was 21.5 (17.3) years (range, 3-64 years). The majority of patients were from the South (50\%), followed by the Northeast and West (21.4\% each) and North Central (7.1\%) areas of the United States.

IUs Dispensed. IUs dispensed were more variable than expenditures, with lower IUs dispensed for the EHL product compared with the SHL product in some 3-month intervals, and greater IUs dispensed for the EHL product than the SHL product in other intervals (Figure 2; Table 2). This same variability was observed when examining the 1-year period before and after switching from the SHL to the EHL product. Fewer units dispensed in the 1- to 3-month interval before switching may represent a drawdown of the patients' personal supply of product in anticipation of the switch from SHL to EHL products. Patients typically order a 1- to 3-month supply so they have factor available in their homes for regular administration and to treat a bleed, should one occur.

Mean IUs dispensed decreased by 3,004 IU, while median IUs dispensed increased by 4,775 IU (Table 3). Factor IUs dispensed over the 3-month periods for individual patients are summarized in Appendix B (available in online article). A reduction in IUs dispensed was expected with the EHL product, as the number of units required according to dosing recommendations is less than that of the SHL product for the same duration of treatment.

Expenditures. Both the mean and median expenditures associated with rFIX replacement product were higher after the switch from the SHL to the EHL product compared with expenditures before the switch for each of the corresponding 3-month (quarterly) time periods (Figure 2; Table 2). Higher expenditures were also observed when examining the entire 1-year period before and after switching from the SHL to the EHL product; mean expenditures increased $\$ 131,748$ and median expenditures increased $\$ 107,303$ (Table 3). Expenditures over the 3-month periods for individual patients are summarized in Appendix B. As expected, clotting factor concentrate expenditures accounted for the majority of total health care expenditures (96\%-100\%).

\section{Discussion}

National health expenditures in the United States grew 5.8\% to $\$ 3.2$ trillion in 2015 , which equates to $\$ 9,900$ per person and accounts for $17.8 \%$ of the Gross Domestic Product. ${ }^{13}$ Projected health spending is expected to be higher than that of the recent past as a result of the changing health care and economic environment and growth in medical prices. Importantly, prescription drug spending increased to \$328 billion in 2015.

The rise in prescription drug spending from 2010 to 2014 was attributed to the following: $10 \%$ increase owing to population growth, 30\% increase because of an increase in the number of prescriptions per person, $30 \%$ increase attributable 
Real-World Analysis of Dispensed IUs of Coagulation Factor IX and Resultant Expenditures in Hemophilia B Patients Receiving Standard Half-Life Versus Extended Half-Life Products and Those Switching from Standard Half-Life to Extended Half-Life Products

TABLE 2 Patient-Level Analysis of Factor Concentrate IUs Dispensed and Expenditures by 3-Month Intervals Before and After Switch from SHL to EHL Product ${ }^{a}$

\begin{tabular}{|c|c|c|c|c|c|c|c|c|c|}
\hline \multirow[b]{2}{*}{ Parameter } & \multicolumn{4}{|c|}{ Months Before Switch } & \multicolumn{5}{|c|}{ Months After Switch } \\
\hline & $\begin{array}{c}10-12 \\
(\mathrm{n}=10)\end{array}$ & $\begin{array}{c}7-9 \\
(n=12)\end{array}$ & $\begin{array}{c}4-6 \\
(n=13)\end{array}$ & $\begin{array}{c}1-3 \\
(n=14)\end{array}$ & & $\begin{array}{c}1-3 \\
(n=14)\end{array}$ & $\begin{array}{c}4-6 \\
(n=14)\end{array}$ & $\begin{array}{c}7-9 \\
(n=9)\end{array}$ & $\begin{array}{l}10-12 \\
(\mathrm{n}=7)\end{array}$ \\
\hline \multicolumn{10}{|l|}{ IUs dispensed } \\
\hline Mean & 61,724 & 90,574 & 106,527 & 54,839 & \multirow{2}{*}{$\begin{array}{c}\mathrm{S} \\
\mathrm{W}\end{array}$} & 88,226 & 54,716 & 57,795 & 61,667 \\
\hline$\overline{\mathrm{SD}}$ & 47,559 & 63,979 & 100,472 & 33,315 & & 66,909 & 39,148 & 47,022 & 58,547 \\
\hline Minimum & 21,000 & 23,680 & 29,080 & 16,160 & \multirow[t]{2}{*}{ I } & 3,724 & 2,636 & 6,477 & 15,204 \\
\hline Lower quartile (25th percentile) & 25,200 & 42,040 & 46,760 & 32,120 & & 26,200 & 23,120 & 19,548 & 18,801 \\
\hline Median & 42,545 & 73,660 & 75,880 & 43,310 & & 74,056 & 45,647 & 50,888 & 43,276 \\
\hline Upper quartile (75th percentile) & 105,045 & 118,900 & 106,900 & 78,000 & \multirow{2}{*}{$\begin{array}{l}\mathrm{C} \\
\mathrm{H}\end{array}$} & 116,096 & 90,930 & 90,930 & 90,749 \\
\hline Maximum & 153,300 & 243,030 & 351,600 & 118,560 & & 214,768 & 113,806 & 140,115 & 180,110 \\
\hline \multicolumn{10}{|l|}{ Expenditures, \$ } \\
\hline Mean & 67,797 & 112,011 & 134,512 & 67,143 & \multirow{2}{*}{$\begin{array}{c}\mathrm{S} \\
\mathrm{W}\end{array}$} & 262,949 & 182,245 & 183,893 & 192,555 \\
\hline $\mathrm{SD}$ & 54,756 & 87,216 & 131,186 & 36,744 & & 180,288 & 106,685 & 138,207 & 149,826 \\
\hline Minimum & 23,741 & 29,237 & 36,337 & 24,884 & \multirow{2}{*}{ I } & 46,719 & 37,483 & 35,244 & 43,730 \\
\hline Lower quartile (25th percentile) & 29,947 & 43,885 & 52,461 & 39,045 & & 140,781 & 83,728 & 67,613 & 70,829 \\
\hline Median & 51,881 & 77,523 & 89,389 & 55,726 & & 205,724 & 183,451 & 147,363 & 173,515 \\
\hline Upper quartile (75th percentile) & 56,853 & 140,741 & 130,326 & 94,376 & C & 352,001 & 275,194 & 311,146 & 242,494 \\
\hline Maximum & 178,090 & 298,841 & 412,591 & 132,654 & $\mathrm{H}$ & 613,494 & 330,834 & 383,655 & 493,181 \\
\hline \multicolumn{10}{|c|}{$\begin{array}{l}\text { Notes: Data presented for the SHL product are specifically for nonacog alfa, and data presented for the EHL product are specifically for eftrenonacog alfa. Expenditures a } \\
\text { based on } 2015 \text { dollars. } \\
\text { aTruven database. }\end{array}$} \\
\hline
\end{tabular}

to overall economy-wide inflation, and 30\% increase owing to changes in drug prescription patterns to higher-priced products or price increases for drugs in excess of inflation rates. ${ }^{14}$ Specialty drug products contributed significantly to the rise in prescription drug spending, increasing annually at a rate of approximately 11\% from $\$ 14.5$ billion in 2009 to $\$ 27.1$ billion in 2015. ${ }^{14}$ In addition, Medicare Part D established a specialty tier threshold of $\$ 600$ out of pocket per individual per month, and drugs that exceeded this price point from 2009 to 2015 had an average 22\% share of prescription drug spending that appears to be rising; the specialty tier threshold was recently increased to $\$ 670$ in $2017 . .^{14}$

Hemophilia is a chronic and costly disease. ${ }^{15}$ Comprehensive care of patients with hemophilia includes visits with the care team of hematologists, physical therapists, registered nurses, and clinical pharmacists, and use of hospital and/or emergency department facilities. ${ }^{15,16}$ However, these factor replacement product expenditures are a small fraction (10\%-15\%) of the total health care expenditures., ${ }^{4,15,17}$ In 2002, Rogoff et al. found that replacement factor prices increased $1.7 \%$ per year over a 9 -year period. ${ }^{18}$ When they controlled for increased factor consumption, the main source of the price increase was the use of new products that were priced an average of $68 \%$ higher than the product that was replaced.
These findings raise questions about whether the advancement in new products is commensurate with increased expenditures. ${ }^{17,19}$ The hemophilia community recognized the theoretical safety difference between plasma-derived and recombinant products and favored recombinant therapies as standard of care. ${ }^{19,20}$ However, with regard to recombinant products, annualized bleeding rates were similar with a once-weekly prophylactic SHL product (3.6) and an EHL product (3.12) in their respective clinical studies. ${ }^{9,11}$ The EHL product was priced to create parity with existing SHL therapies on an annual therapy expenditures basis, understanding that dispensed factor data were derived from selected clinical trials and proprietary pharmacy surveys. ${ }^{21,22}$ Since the EHL product is dosed with fewer weekly IUs, the price per IU was set higher. ${ }^{12}$

Achievement of pricing parity would necessitate, across all users, a reduction in IU use of approximately 63\% following a switch from a twice-weekly regimen using an SHL rFIX product to a once-weekly regimen using an EHL rFIX product ${ }^{21}$; if a weekly dosing strategy is considered, a 50\% reduction would be required, as the recommended dosing with an EHL rFIX product is approximately half that of an SHL rFIX product (EHL, $50 \mathrm{IU} / \mathrm{kg}$ weekly; ${ }^{8}$ SHL, $100 \mathrm{IU} / \mathrm{kg}$ weekly ${ }^{6}$ ). It is notable that 1 of the 2 recommended dosing strategies in the EHL product's labeling (100 IU/kg every 10 days vs. 50 IU/kg/week $)^{8}$ would 
Real-World Analysis of Dispensed IUs of Coagulation Factor IX and Resultant Expenditures in Hemophilia B Patients Receiving Standard Half-Life Versus Extended Half-Life Products and Those Switching from Standard Half-Life to Extended Half-Life Products

\section{TABLE 3 Patient-Level Analysis of Factor Concentrate IUs Dispensed and Expenditures for 1 Year Before and} 1 Year After Switching from the SHL to the EHL Product ${ }^{a}$

\begin{tabular}{|c|c|c|c|c|c|c|}
\hline \multirow[b]{2}{*}{ Parameter } & \multicolumn{3}{|c|}{ IUs Dispensed } & \multicolumn{3}{|c|}{ Expenditures, \$ } \\
\hline & $\begin{array}{l}\text { Before Switch } \\
\text { (SHL Use) }\end{array}$ & $\begin{array}{l}\text { After Switch } \\
\text { (EHL Use) }\end{array}$ & $\begin{array}{l}\text { Change in IUs } \\
\text { After Switch from } \\
\text { SHL to EHL }\end{array}$ & $\begin{array}{l}\text { Before Switch } \\
\text { (SHL Use) }\end{array}$ & $\begin{array}{l}\text { After Switch } \\
\text { (EHL Use) }\end{array}$ & $\begin{array}{c}\text { Increased } \\
\text { Expenditures } \\
\text { (SHL to EHL } \\
\text { Switch) }\end{array}$ \\
\hline Mean & 80,923 & 77,919 & $-3,004$ & 99,718 & 231,466 & 131,748 \\
\hline$\overline{\mathrm{SD}}$ & 57,052 & 59,816 & 2,764 & 66,534 & 163,923 & 97,389 \\
\hline Minimum & 32,120 & 7,910 & $-24,210$ & 39,045 & 46,719 & 7,674 \\
\hline Lower quartile (25th percentile) & 39,375 & 27,978 & $-11,398$ & 51,157 & 115,689 & 64,532 \\
\hline Median & 59,623 & 64,398 & 4,775 & 75,861 & 183,164 & 107,303 \\
\hline Upper quartile (75th percentile) & 101,965 & 113,144 & 11,179 & 127,928 & 330,650 & 202,722 \\
\hline Maximum & 233,200 & 214,768 & $-18,432$ & 266,225 & 613,494 & 347,269 \\
\hline
\end{tabular}

Notes: Data presented for the SHL product are specifically for nonacog alfa, and data presented for the EHL product are specifically for eftrenonacog alfa. Expenditures are based on 2015 dollars.

aTruven database.

$E H L=$ extended half-life; IUs=international units; $S D=$ standard deviation; $S H L=$ standard half-life.

actually result in $40 \%$ more monthly use than the other strategy and would incur a commensurate increase in expenditures. ${ }^{21}$

Results of our analysis provide further information about IUs of factor dispensed and about expenditures for these rFIX replacement products. From the population-level view, the national specialty pharmacy database profiled data for a large number of patients over the 15-month study period, documenting lower IUs dispensed (11\%) and higher expenditures (94\%) for the EHL product compared with the SHL product. Expenditures were uniformly higher with the EHL product use across prophylaxis and episodic (on-demand) regimen patients; in addition, episodic on-demand patients had more EHL than SHL factor IUs dispensed (1,914; 15\%), possibly related to guidance in the EHL product's labeling advising a higher target FIX activity in the setting of uncomplicated hemarthrosis. ${ }^{8}$

The numbers of episodic on-demand patients were small, as would be expected, since the majority of EHL product use is in the prophylaxis patient group. Real-world experience with the EHL product is limited, but the median weekly prophylactic dose in the pivotal clinical study was $47.3 \mathrm{IU} / \mathrm{kg} /$ week, which translates to $13,244 \mathrm{IU}$ per month for a $70-\mathrm{kg}$ person. ${ }^{23}$ The national specialty pharmacy data showed median monthly EHL product IUs dispensed ranging from 16,340 IU to $20,912 \mathrm{IU}$, suggesting that real-world consumption may be greater than expected.

The Truven database identified a small number of patients who served as their own controls and were followed over time as they switched from the SHL to the EHL product. The examples of greater-than-anticipated IUs dispensed for the EHL product in this component of the analysis-that is, a dispensation that failed to comprise at least a 50\% reduction from the patient's baseline on the SHL product, before the switch-may disrupt the paradigm of pricing parity and drive higher expenditures. Even in cases of a 30\% reduction in mean IUs dispensed, for instance, a mean expenditure increase of 54\% would result (Figure 1). When comparing the 3-month period after switching from the SHL to the EHL product to the 3-month period before, we found that IUs dispensed and expenditures for the EHL product were consistently higher.

These findings run counter to the expected lower dispensed factor and expenditure parity for the EHL product and may be related to the complex pharmacokinetics of rFIX replacement products and lack of known translation between half-life for the SHL product to that for the EHL product in individual patients. ${ }^{21}$ Transitioning from an SHL to an EHL product may require pharmacokinetic analysis to comprehensively assess each patient's needs, leading to variability in the dosing to achieve optimal outcomes. ${ }^{21}$ For prophylaxis specifically, the increased expenditures observed in this analysis may be in part attributable to higher IUs dispensed than would be expected based on dosing published in the literature in the case of the EHL product, and to lower-than-postulated IUs dispensed for the SHL product. ${ }^{23}$ This finding also contrasts with an anticipated reduction in factor use based on eftrenonacog alfa dosing, used to establish its pricing structure..$^{12,21}$

\section{Limitations}

The retrospective nature of this analysis is a limitation but was intended to provide a basis for understanding the current evolving treatments for hemophilia B. The challenges associated with data acquisition in rare diseases are based on their small sample sizes and geographically diverse populations, as well as evidence gaps related to the natural history and course 
of the disease. ${ }^{24}$ Study samples were not randomly assigned, which may have introduced a treatment choice bias.

Because approximately $80 \%$ of the patients were $<40$ years of age and 63\% of patients had their disease reported as severe, we cannot opine on the implications for older patients and for those with moderate or mild hemophilia B. The databases provided information for claims payments, not for research; thus, in most cases, variables such as patient weight, disease characteristics, fidelity to treatment regimen, and number of bleeding events (if any) are unknown or were not present in all databases. Additionally, with regard to expenditures, the effects of other, subsequent discounts not already captured in the Truven data (if any) or distribution expenditures are unknown.

Prospective data analyzing SHL and EHL products with a well-characterized patient population (e.g., weight, treatment regimens, and bleeding events) are needed. In addition, it cannot be assumed, based on prescription data, that the prescribed units were infused.

\section{Conclusions}

This analysis of real-world data shows that expenditures associated with the use of an EHL rFIX replacement product, including in the prophylaxis setting, were higher than expenditures with the SHL product. Additional studies with larger sample sizes are needed to examine the hypotheses generated from this real-world data analysis.

\section{Authors}

BARTHOLOMEW J. TORTELLA, MD, MBA, and PATRICK F. FOGARTY, MD, Medical Affairs, Pfizer, Collegeville, Pennsylvania. JOSÉ ALVIR, DrPH, Statistical Research and Data Science Center, Global Product Development; MARGARET MCDONALD, PhD, Patient and Health Impact; and AMIT CHHABRA, MBBS, MPH, Medical Affairs, Pfizer, New York, New York. DEAN SPURDEN, $P h D$, Patient and Health Impact, Pfizer, Tadworth, Surrey, United Kingdom, and ANDREAS M. PLEIL, PhD, Patient and Health Impact, Pfizer, San Diego, California.

AUTHOR CORRESPONDENCE: Bartholomew J. Tortella, MD, MBA, Pfizer, 500 Arcola Rd., Collegeville, PA 19073.

Tel.: 484.865.5590; E-mail: Bartholomew.J.Tortella@pfizer.com.

\section{DISCLOSURES}

This study was sponsored by Pfizer. Pfizer employees were involved in the study design; the collection, analysis, and interpretation of data; the review of the manuscript; and the decision to submit for publication. All authors are employees of Pfizer. No author received an honorarium or other form of payment related to the development of this manuscript.

Data from this paper were presented in part at the European Association for Haemophilia and Allied Disorders Annual Meeting, February 1-3, 2017, Paris, France; at the International Society for Pharmacoeconomics and Outcomes Research Annual Meeting, May 20-24, 2017, Boston, MA; and at the International Society on Thrombosis and Haemostasis Congress, July 8-13, 2017, Berlin, Germany.

\section{ACKNOWLEDGMENTS}

The authors thank Bina J. Patel, PharmD, and Michelle McDermott, PharmD, of Peloton Advantage, Parsippany, NJ, for medical writing and editorial support, which was funded by Pfizer.

\section{REFERENCES}

1. Srivastava A, Brewer AK, Mauser-Bunschoten EP, et al. Guidelines for the management of hemophilia. Haemophilia. 2013;19(1):el-47.

2. Franchini M, Frattini F, Crestani S, Sissa C, Bonfanti C. Treatment of hemophilia B: focus on recombinant factor IX. Biologics. 2013;7:33-38

3. White GC, Rosendaal F, Aledort LM, Lusher JM, Rothschild C, Ingerslev J Definitions in hemophilia. Recommendation of the scientific subcommittee on factor VIII and factor IX of the scientific and standardization committee of the International Society on Thrombosis and Haemostasis. Thromb Haemost. 2001;85(3):560

4. Chen SL. Economic costs of hemophilia and the impact of prophylactic treatment on patient management. Am J Manag Care. 2016;22(5 Suppl):s126-33.

5. Harrison S, Adamson S, Bonam D, et al. The manufacturing process for recombinant factor IX. Semin Hematol. 1998;35(2 Suppl 2):4-10.

6. BeneFIX [package insert]. Philadelphia, PA: Wyeth Pharmaceuticals (Pfizer). 2015.

7. Hua B, Wu R, Sun F, et al. Confirmation of longer FIX activity half-life with prolonged sample collection after single doses of nonacog alfa in patients with haemophilia B. Thromb Haemost. 2017;117(6):1052-57.

8. Alprolix [package insert]. Cambridge, MA: Biogen; 2017

9. Powell JS, Pasi KJ, Ragni MV, et al. Phase 3 study of recombinant factor IX Fc fusion protein in hemophilia B. N Engl J Med. 2013;369(24):2313-23.

10. Peyvandi F, Garagiola I, Young G. The past and future of haemophilia: diagnosis, treatments, and its complications. Lancet. 2016;388(10040):187-97.

11. Kavakli K, Smith L, Kuliczkowski K, et al. Once-weekly prophylactic treatment versus on-demand treatment with nonacog alfa in patients with moderately severe to severe hemophilia B. Haemophilia. 2016;22(3):381-88.

12. Berkrot B. Exclusive: Biogen prices hemophilia drug on par with older therapies. 2014. Available at: www.reuters.com/article/us-biogen-hemophilia-idUSBREA3HOKL20140418. Accessed December 26, 2017.

13. National health expenditure 2015 fact sheet. Baltimore, MD: Centers for Medicare and Medicaid Services, 2018.

14. U.S. Department of Health \& Human Services. ASPE issue brief. Observations on trends in prescription drug spending. 2016. Available at: https://aspe.hhs.gov/sites/default/files/pdf/187586/Drugspending.pdf. Accessed December 26, 2017.

15. Aledort LM. Economics of hemophilia care. Haemostasis. 2000;30(6):333-36.

16. Carlson DL, Heaton A, Portuese E. Improving the care of hemophiliacs by managing the drug benefit. Am J Health Syst Pharm. 1999;56(13):1303-05. 
Real-World Analysis of Dispensed IUs of Coagulation Factor IX and Resultant Expenditures in Hemophilia B Patients Receiving Standard Half-Life Versus Extended Half-Life Products and Those Switching from Standard Half-Life to Extended Half-Life Products

17. Aledort LM. Can costs of hemophilia products be curtailed? Not as we do business today! Thromb Haemost. 2002;88(4):541.

18. Rogoff EG, Guirguis HS, Lipton RA, et al. The upward spiral of drug costs: a time series analysis of drugs used in the treatment of hemophilia. Thromb Haemost. 2002;88(4):545-53.

19. Kletter SD, Rankin PJ. Cost trends in the treatment for hemophilia: another view. Thromb Haemost. 2002;88(4):542-44.

20. National Hemophilia Foundation. MASAC recommendation regarding the use of recombinant clotting factor replacement therapies (\#106). 2000. Available at: https://www.hemophilia.org/sites/default/files/document/files/ masac106.pdf. Accessed December 26, 2017.
21. Croteau SE, Neufeld EJ. Transition considerations for extended half-life factor products. Haemophilia. 2015;21(3):285-88.

22. Croteau SE, Neufeld EJ. Author's response: 'Transition considerations for extended half-life factor products.' Haemophilia. 2015;21(5):e454-55.

23. Krishnan S, Buckley B, Brennan A, Wong WY. Response to Croteau \& Neufeld editorial: 'Transition considerations for extended half-life factor products.' Haemophilia. 2015;21(5):e451-53.

24. Gliklich R, Palucci O. Generating real-world evidence for rare diseases. ISPOR Connections. 2012. Available at: ispor.org/news/articles/april12/ generating-real-world-evidence.asp. Accessed December 26, 2017. 
Real-World Analysis of Dispensed IUs of Coagulation Factor IX and Resultant Expenditures in Hemophilia B Patients Receiving Standard Half-Life Versus Extended Half-Life Products and Those Switching from Standard Half-Life to Extended Half-Life Products

\section{APPENDIX A Population-Level Analysis of Median and Mean IUs Dispensed and Monthly Expenditures of} Recombinant Factor IX Replacement Products

\begin{tabular}{|c|c|c|c|c|c|c|c|c|c|c|c|c|c|c|c|}
\hline Parameter & $\begin{array}{c}\text { Apr } \\
2015 \\
(\mathbf{n}=114)\end{array}$ & $\begin{array}{c}\text { May } \\
2015 \\
(\mathbf{n}=118)\end{array}$ & $\begin{array}{c}\text { Jun } \\
2015 \\
(\mathbf{n}=12)\end{array}$ & $\begin{array}{c}\text { Jul } \\
2015 \\
(\mathbf{n}=121)\end{array}$ & $\begin{array}{c}\text { Aug } \\
2015 \\
(\mathrm{n}=118)\end{array}$ & $\begin{array}{c}\text { Sep } \\
2015 \\
(\mathbf{n}=129)\end{array}$ & $\begin{array}{c}\text { Oct } \\
2015 \\
(\mathbf{n}=133)\end{array}$ & $\begin{array}{c}\text { Nov } \\
2015 \\
(\mathrm{n}=113)\end{array}$ & $\begin{array}{c}\text { Dec } \\
2015 \\
(\mathrm{n}=130)\end{array}$ & $\begin{array}{c}\text { Jan } \\
2016 \\
(\mathrm{n}=115)\end{array}$ & $\begin{array}{c}\text { Feb } \\
2016 \\
(\mathbf{n}=108)\end{array}$ & $\begin{array}{c}\text { Mar } \\
2016 \\
(\mathrm{n}=128)\end{array}$ & $\begin{array}{c}\text { Apr } \\
2016 \\
(\mathrm{n}=115)\end{array}$ & $\begin{array}{c}\text { May } \\
2016 \\
(\mathrm{n}=120)\end{array}$ & $\begin{array}{c}\text { Jun } \\
2016 \\
(\mathbf{n}=119)\end{array}$ \\
\hline \multicolumn{16}{|c|}{ Median and mean IUs dispensed } \\
\hline EHL cohort, $\mathrm{n}$ & 32 & 35 & 42 & 37 & 42 & 46 & 50 & 39 & 54 & 48 & 43 & 54 & 46 & 50 & 51 \\
\hline Median & 17,327 & 20,912 & 19,183 & 17,340 & 18,924 & 17,340 & 17,868 & 19,512 & 17,883 & 18,426 & 18,426 & 18,426 & 16,340 & 18,354 & 20,412 \\
\hline IQR & \begin{tabular}{|l}
$12,522-$ \\
36,372 \\
\end{tabular} & \begin{tabular}{|l}
$10,524-$ \\
28,767 \\
\end{tabular} & $\begin{array}{l}12,124- \\
38,220 \\
\end{array}$ & \begin{tabular}{|l|}
$10,070-$ \\
25,416
\end{tabular} & \begin{tabular}{|l|}
$12,124-$ \\
28,122 \\
\end{tabular} & \begin{tabular}{|l|}
$10,070-$ \\
28,122 \\
\end{tabular} & $\begin{array}{l}10,070- \\
33,814 \\
\end{array}$ & \begin{tabular}{|l}
$10,656-$ \\
34,680 \\
\end{tabular} & \begin{tabular}{|l|}
$10,600-$ \\
32,680 \\
\end{tabular} & $\begin{array}{l}10,628- \\
26,707 \\
\end{array}$ & $\begin{array}{l}8,112- \\
31,146\end{array}$ & \begin{tabular}{|l}
$12,264-$ \\
36,852 \\
\end{tabular} & \begin{tabular}{|l|}
$10,220-$ \\
25,122 \\
\end{tabular} & \begin{tabular}{|l|}
$11,424-$ \\
36,708 \\
\end{tabular} & $\begin{array}{l}2,516- \\
36,708 \\
\end{array}$ \\
\hline Mean (SD) & \begin{tabular}{|l|}
28,949 \\
$(29,741)$
\end{tabular} & $\begin{array}{c}23,861 \\
(18,387)\end{array}$ & $\begin{array}{c}26,440 \\
(20,288)\end{array}$ & $\begin{array}{c}19,561 \\
(13,554)\end{array}$ & $\begin{array}{c}22,963 \\
(17,059)\end{array}$ & \begin{tabular}{|c|}
23,383 \\
$(24,379)$
\end{tabular} & $\begin{array}{c}26,045 \\
(26,952)\end{array}$ & $\begin{array}{c}23,674 \\
(18,327)\end{array}$ & $\begin{array}{c}23,135 \\
(16,718)\end{array}$ & $\begin{array}{l}21,491 \\
(15,144)\end{array}$ & $\begin{array}{c}22,210 \\
(16,954)\end{array}$ & $\begin{array}{c}25,923 \\
(21,921)\end{array}$ & $\begin{array}{c}21,757 \\
(22,399)\end{array}$ & $\begin{array}{c}23,997 \\
(17,635)\end{array}$ & $\begin{array}{c}25,016 \\
(17,295)\end{array}$ \\
\hline SHL cohort, $n$ & 83 & 85 & 90 & 85 & 76 & 86 & 84 & 74 & 76 & 67 & 67 & 74 & 69 & 70 & 68 \\
\hline Median & 30,600 & 30,750 & 31,590 & 30,500 & 30,300 & 30,360 & 32,520 & 32,271 & 34,158 & 34,940 & 34,080 & 34,141 & 29,776 & 33,660 & 32,569 \\
\hline IQR & $\begin{array}{c}12,800- \\
43,560\end{array}$ & $\begin{array}{c}14,960- \\
47,250\end{array}$ & $\begin{array}{l}15,840- \\
50,520\end{array}$ & $\begin{array}{c}18,700- \\
45,172\end{array}$ & $\begin{array}{l}15,915- \\
45,522\end{array}$ & $\begin{array}{c}15,900- \\
48,480\end{array}$ & $\begin{array}{c}20,070- \\
51,482\end{array}$ & \begin{tabular}{|l|}
$17,446-$ \\
56,352
\end{tabular} & \begin{tabular}{|l|}
$17,436-$ \\
49,920
\end{tabular} & $\begin{array}{l}20,800- \\
52,380\end{array}$ & $\begin{array}{c}21,300- \\
59,220\end{array}$ & $\begin{array}{c}21,300- \\
55,616\end{array}$ & \begin{tabular}{|c|}
$18,438-$ \\
43,748
\end{tabular} & $\begin{array}{c}20,456- \\
57,950\end{array}$ & $\begin{array}{l}16,520- \\
65,920\end{array}$ \\
\hline Mean (SD) & $\begin{array}{c}36,943 \\
(32,773) \\
\end{array}$ & $\begin{array}{c}37,382 \\
(30,916) \\
\end{array}$ & $\begin{array}{c}44,090 \\
(52,473) \\
\end{array}$ & $\begin{array}{c}40,139 \\
(44,872) \\
\end{array}$ & \begin{tabular}{|c|}
41,102 \\
$(47,882)$ \\
\end{tabular} & $\begin{array}{c}39,175 \\
(42,357) \\
\end{array}$ & \begin{tabular}{|c|}
46,260 \\
$(60,467)$ \\
\end{tabular} & $\begin{array}{c}44,755 \\
(49,565) \\
\end{array}$ & \begin{tabular}{|c|}
44,169 \\
$(40,634)$ \\
\end{tabular} & $\begin{array}{c}42,751 \\
(43,909) \\
\end{array}$ & $\begin{array}{c}45,614 \\
(48,354) \\
\end{array}$ & $\begin{array}{c}47,022 \\
(63,642) \\
\end{array}$ & \begin{tabular}{|c|}
38,775 \\
$(44,312)$ \\
\end{tabular} & \begin{tabular}{|c|}
42,892 \\
$(44,740)$ \\
\end{tabular} & $\begin{array}{c}46,821 \\
(51,390) \\
\end{array}$ \\
\hline $\begin{array}{l}\text { Difference in } \\
\text { median IUs } \\
\text { dispensed } \\
\text { (EHL-SHL) }\end{array}$ & $-13,273$ & $-9,838$ & $-12,407$ & $-13,160$ & $-11,376$ & $-13,020$ & $-14,652$ & $-12,759$ & $-16,275$ & $-16,514$ & $-15,654$ & $-15,715$ & $-13,436$ & $-15,306$ & 12,157 \\
\hline $\begin{array}{l}\text { \% difference } \\
\text { in median } \\
\text { IUs dispensed } \\
\text { (EHL-SHL) }\end{array}$ & -43 & -32 & -39 & -43 & -38 & -43 & -45 & -40 & -48 & -47 & -46 & -46 & -45 & -45 & 37 \\
\hline
\end{tabular}

Median and mean monthly expenditures, \$

\begin{tabular}{|c|c|c|c|c|c|c|c|c|c|c|c|c|c|c|c|}
\hline EHL cohort, $\mathrm{n}$ & 32 & 35 & 42 & 37 & 42 & 46 & 50 & 39 & 54 & 48 & 43 & 54 & 46 & 50 & 51 \\
\hline Median & 49,382 & 59,599 & 54,672 & 49,419 & 53,933 & 49,419 & 50,924 & 55,609 & 50,967 & 52,514 & 52,514 & 52,514 & 46,569 & 52,309 & 58,174 \\
\hline IQR & \begin{tabular}{|l|}
$35,688-$ \\
103,660
\end{tabular} & $\begin{array}{c}29,993- \\
81,986\end{array}$ & $\begin{array}{l}34,553- \\
108,927\end{array}$ & $\begin{array}{c}28,700- \\
72,436\end{array}$ & $\begin{array}{c}34,553- \\
80,148\end{array}$ & $\begin{array}{c}28,700- \\
80,148\end{array}$ & $\begin{array}{c}28,700- \\
96,370\end{array}$ & $\begin{array}{l}30,370- \\
98,838 \\
\end{array}$ & $\begin{array}{l}30,210- \\
93,138 \\
\end{array}$ & $\begin{array}{c}30,290- \\
76,114\end{array}$ & $\begin{array}{l}23,119- \\
88,766\end{array}$ & $\begin{array}{l}34,952- \\
105,028\end{array}$ & $\begin{array}{l}29,127- \\
71,598 \\
\end{array}$ & $\begin{array}{l}32,558- \\
104,618\end{array}$ & $\begin{array}{l}35,671- \\
104,618\end{array}$ \\
\hline Mean (SD) & $\begin{array}{c}82,506 \\
(84,763) \\
\end{array}$ & $\begin{array}{c}68,004 \\
(52,402) \\
\end{array}$ & $\begin{array}{c}75,354 \\
(57,822) \\
\end{array}$ & $\begin{array}{c}55,750 \\
(38,629)\end{array}$ & $\begin{array}{c}65,446 \\
(48,619) \\
\end{array}$ & $\begin{array}{c}66,640 \\
(69,481) \\
\end{array}$ & $\begin{array}{c}74,227 \\
(76,815) \\
\end{array}$ & $\begin{array}{c}67,472 \\
(52,232) \\
\end{array}$ & $\begin{array}{c}65,935 \\
(47,647)\end{array}$ & $\begin{array}{c}61,250 \\
(43,160)\end{array}$ & $\begin{array}{c}63,298 \\
(48,320)\end{array}$ & \begin{tabular}{|c|}
73,881 \\
$(62,474)$ \\
\end{tabular} & $\begin{array}{c}62,008 \\
(63,837) \\
\end{array}$ & $\begin{array}{c}68,391 \\
(50,259) \\
\end{array}$ & $\begin{array}{c}71,295 \\
(49,291) \\
\end{array}$ \\
\hline SHL cohort, $n$ & 83 & 85 & 90 & 85 & 76 & 86 & 84 & 74 & 76 & 67 & 67 & 74 & 69 & 70 & 68 \\
\hline Median & 39,780 & 39,975 & 41,067 & 39,650 & 39,390 & 39,468 & 42,276 & 41,952 & 44,405 & 45,422 & 44,304 & 44,383 & 38,709 & 43,758 & 42,339 \\
\hline IQR & \begin{tabular}{|c|}
$16,640-$ \\
56,628
\end{tabular} & \begin{tabular}{|c|}
$19,448-$ \\
61,425
\end{tabular} & $\begin{array}{c}20,592- \\
65,676 \\
\end{array}$ & \begin{tabular}{|c|}
$24,310-$ \\
58,724 \\
\end{tabular} & \begin{tabular}{|c|}
$20,690-$ \\
59,179 \\
\end{tabular} & \begin{tabular}{|c|}
$20,670-$ \\
63,024 \\
\end{tabular} & \begin{tabular}{|c|}
$26,091-$ \\
66,926 \\
\end{tabular} & $\begin{array}{c}22,680- \\
73,258\end{array}$ & $\begin{array}{l}22,667- \\
64,896 \\
\end{array}$ & $\begin{array}{l}27,040- \\
68,094\end{array}$ & $\begin{array}{l}27,690- \\
76,986 \\
\end{array}$ & $\begin{array}{c}27,690- \\
72,301 \\
\end{array}$ & $\begin{array}{c}23,969- \\
56,872 \\
\end{array}$ & $\begin{array}{c}26,593- \\
75,335\end{array}$ & \begin{tabular}{|l|}
$21,476-$ \\
85,696 \\
\end{tabular} \\
\hline Mean (SD) & $\begin{array}{c}48,026 \\
(42,604)\end{array}$ & $\begin{array}{c}48,596 \\
(40,190) \\
\end{array}$ & $\begin{array}{c}57,317 \\
(68,214) \\
\end{array}$ & $\begin{array}{c}52,181 \\
(58,333) \\
\end{array}$ & $\begin{array}{c}53,433 \\
(62,247) \\
\end{array}$ & $\begin{array}{c}50,927 \\
(55,065) \\
\end{array}$ & $\begin{array}{c}60,137 \\
(78,607) \\
\end{array}$ & $\begin{array}{c}58,181 \\
(64,434) \\
\end{array}$ & $\begin{array}{c}57,420 \\
(52,824)\end{array}$ & $\begin{array}{c}55,576 \\
(57,081) \\
\end{array}$ & $\begin{array}{c}59,298 \\
(62,860) \\
\end{array}$ & $\begin{array}{c}61,128 \\
(82,734)\end{array}$ & $\begin{array}{c}50,408 \\
(57,606) \\
\end{array}$ & $\begin{array}{c}55,760 \\
(58,162) \\
\end{array}$ & \begin{tabular}{|c|}
60,867 \\
$(66,807)$ \\
\end{tabular} \\
\hline $\begin{array}{l}\text { Difference } \\
\text { in median } \\
\text { expenditures } \\
\text { (EHL-SHL) }\end{array}$ & 9,602 & 19,624 & 13,605 & 9,769 & 14,543 & 9,951 & 8,648 & 13,657 & 6,562 & 7,092 & 8,210 & 8,131 & 7,860 & 8,551 & 15,835 \\
\hline $\begin{array}{l}\text { \% median } \\
\text { expenditure } \\
\text { difference } \\
\text { (EHL-SHL) }\end{array}$ & 24 & 49 & 33 & 25 & 37 & 25 & 20 & 33 & 15 & 16 & 19 & 18 & 20 & 20 & 37 \\
\hline
\end{tabular}

Notes: Data presented for the SHL product are specifically for nonacog alfa, and data presented for the EHL product are specifically for eftrenonacog alfa. Expenditures are based on 2015 dollars.

${ }^{a}$ National Specialty Pharmacy Database.

$E H L=$ extended half-life; $I Q R=$ interquartile range; $I U s=$ international units; $S D=$ standard deviation; $S H L=$ standard half-life. 
Real-World Analysis of Dispensed IUs of Coagulation Factor IX and Resultant Expenditures in Hemophilia B Patients Receiving Standard Half-Life Versus Extended Half-Life Products and Those Switching from Standard Half-Life to Extended Half-Life Products

APPENDIX B Individual Patient IUs Dispensed and Factor Concentrate Expenditures by 3-Month Intervals Before and After Switch from the SHL to EHL Product ${ }^{2}$

\begin{tabular}{|c|c|c|c|c|c|c|c|c|c|c|c|}
\hline \multirow[b]{2}{*}{ Patient } & \multicolumn{4}{|c|}{$\begin{array}{c}\text { SHL Treatment Period } \\
\text { (Before Switch to EHL Product) }\end{array}$} & \multicolumn{5}{|c|}{$\begin{array}{c}\text { EHL Treatment Period } \\
\text { (After Switch from SHL Product) }\end{array}$} & \multicolumn{2}{|c|}{ All Available Quarters } \\
\hline & 4th Qtr & 3rd Qtr & 2nd Qtr & 1st Qtr & & 1st Qtr & 2nd Qtr & 3rd Qtr & 4th Qtr & $\begin{array}{l}\text { Before } \\
\text { Switch }\end{array}$ & After Switch \\
\hline \multicolumn{12}{|c|}{ Individual patient IUs dispensed } \\
\hline 1 & 35,300 & 48,960 & 48,960 & 16,160 & \multirow{6}{*}{$\mathrm{s}$} & 59,360 & 72,080 & - & - & 37,345 & 65,720 \\
\hline 2 & 47,840 & 35,120 & 29,080 & 22,058 & & 26,064 & 13,032 & 19,548 & 15,204 & 33,525 & 18,462 \\
\hline 3 & 153,300 & 102,700 & 101,500 & 50,360 & & 70,304 & 35,152 & - & - & 101,965 & 52,728 \\
\hline 4 & 25,200 & 23,680 & 46,760 & 71,040 & & 26,200 & 30,310 & 12,124 & 43,276 & 41,670 & 27,978 \\
\hline 5 & 21,000 & 243,030 & 291,440 & 45,920 & & 103,964 & 87,032 & 112,092 & 58,578 & 150,348 & 90,417 \\
\hline 6 & - & 51,010 & 76,110 & 25,870 & & 16,224 & - & - & - & 50,997 & 16,224 \\
\hline 7 & 105,045 & 163,268 & 75,880 & 32,480 & \multirow[b]{4}{*}{ C } & 148,290 & 113,806 & - & - & 94,168 & 131,048 \\
\hline 8 & - & - & 122,160 & 118,560 & & 98,250 & 90,930 & 90,930 & 90,749 & 120,360 & 92,715 \\
\hline 9 & 21,100 & 34,000 & 61,700 & 40,700 & & 77,808 & 56,142 & 55,278 & - & 39,375 & 63,076 \\
\hline 10 & 46,090 & 65,920 & 33,760 & 35,360 & & 61,612 & 23,120 & 50,888 & 24,952 & 45,283 & 40,143 \\
\hline 11 & - & - & - & 32,120 & \multirow[t]{5}{*}{$\mathrm{H}$} & 214,768 & - & - & - & 32,120 & 214,768 \\
\hline $12^{\mathrm{b}}$ & 39,000 & 117,000 & 39,000 & 78,000 & & 3,724 & 2,636 & 6,477 & 18,801 & 68,250 & 7,910 \\
\hline 13 & - & - & - & 84,322 & & 116,096 & 110,192 & - & - & 84,322 & 113,144 \\
\hline 14 & - & - & 351,600 & 114,800 & & 212,505 & 93,390 & 140,115 & 180,110 & 233,200 & 156,530 \\
\hline Median & 39,000 & 58,465 & 68,790 & 43,310 & & 74,056 & 64,111 & 53,083 & 43,276 & 59,623 & 64,398 \\
\hline \multicolumn{12}{|c|}{ Factor concentrate expenditures, \$ } \\
\hline 1 & $51,880.99$ & $75,392.34$ & $75,392.33$ & $24,884.39$ & \multirow{7}{*}{ S } & $178,649.81$ & $216,931.90$ & - & - & $56,887.51$ & $197,790.86$ \\
\hline 2 & $56,852.94$ & $43,884.97$ & $36,336.85$ & $27,562.53$ & & $75,072.86$ & $37,482.88$ & $56,224.32$ & $43,730.04$ & $41,159.32$ & $53,127.53$ \\
\hline 3 & $178,090.41$ & $119,307.79$ & $123,982.82$ & $61,515.02$ & & $203,474.50$ & $103,389.00$ & - & - & $120,724.01$ & $153,431.75$ \\
\hline 4 & $29,947.31$ & $29,237.02$ & $57,733.25$ & $87,711.06$ & & $68,975.82$ & $88,111.16$ & $35,244.47$ & $125,803.32$ & $51,157.16$ & $79,533.69$ \\
\hline 5 & $24,490.20$ & $298,840.60$ & $412,591.48$ & $65,008.90$ & & $352,001.19$ & $294,672.88$ & $379,521.00$ & $198,333.32$ & $200,232.80$ & $306,132.10$ \\
\hline 6 & - & $69,469.48$ & $103,652.66$ & $35,231.82$ & & $46,719.24$ & - & - & - & $69,451.32$ & $46,719.24$ \\
\hline 7 & $142,703.62$ & $221,799.52$ & $103,082.94$ & $44,124.06$ & & $431,078.87$ & $330,833.94$ & - & - & $127,927.54$ & $380,956.41$ \\
\hline 8 & - & - & $136,669.66$ & $132,654.22$ & & $262,297.75$ & $242,771.00$ & $242,771.00$ & $242,494.34$ & $134,661.94$ & $247,583.52$ \\
\hline 9 & $23,741.14$ & $41,783.61$ & $75,695.17$ & $49,936.17$ & \multirow[b]{2}{*}{ C } & $207,972.97$ & $149,970.50$ & $147,665.75$ & - & $47,789.02$ & $168,536.41$ \\
\hline 10 & $55,692.83$ & $79,654.41$ & $40,793.88$ & $42,727.25$ & & $178,052.44$ & $66,814.44$ & $147,061.19$ & $70,828.75$ & $54,717.09$ & $115,689.21$ \\
\hline 11 & - & - & - & $39,044.84$ & \multirow[t]{5}{*}{$\mathrm{H}$} & $613,494.27$ & - & - & - & $39,044.84$ & $613,494.27$ \\
\hline $12^{\mathrm{b}}$ & $46,776.34$ & $140,740.68$ & $47,188.00$ & $94,376.00$ & & $140,780.54$ & $79,345.06$ & $79,001.97$ & $173,515.40$ & $82,270.26$ & $118,160.74$ \\
\hline 13 & - & - & - & $103,798.48$ & & $340,398.57$ & $320,901.11$ & - & - & $103,798.48$ & $330,649.84$ \\
\hline 14 & - & - & $401,019.39$ & $131,431.13$ & & $582,313.29$ & $255,715.01$ & $383,654.64$ & $493,180.88$ & $266,225.26$ & $428,715.96$ \\
\hline Median & $51,880.99$ & $77,523.38$ & $89,389.06$ & $55,725.60$ & & $205,723.74$ & $183,451.20$ & $147,363.47$ & $173,515.40$ & $75,860.79$ & $183,163.63$ \\
\hline \multicolumn{12}{|c|}{$\begin{array}{l}\text { Notes: Data presented for the SHL product are specifically for nonacog alfa and data presented for the EHL product are specifically for eftrenonacog alfa. Expend } \\
\text { based on } 2015 \text { dollars. } \\
\text { aTruven database. } \\
\text { bPatient } 12 \text { manifested low units dispensed but high expenditures, which may represent nonalignment between unit dispensation and actual posting of payments. } \\
\text { EHL=extended half-life; IUs = international units; Qtr=quarter; SHL= standard half-life. }\end{array}$} \\
\hline
\end{tabular}

